\title{
Discussion on the Influence of Modern Education Technology on the Teaching of Chinese Language and Literature
}

\author{
Chen Rui \\ Inner Mongolia Vocational College of Physical Education, Hohhot 010010 China
}

Keywords: Chinese language and literature; modern education technology; teaching influence; Internet

\begin{abstract}
With the progress of the times and the development of science and technology, education industry has been impacted by modern education technology. In the process of gradual integration and acceptance of education technology, education industry gradually formed a new education mode and education mode. This formed the educational industry education teaching reform. Taking Chinese language and literature as an example, this paper studies the development and changes of education system under the impact of modern education technology by analyzing the influence of modern education technology on Chinese language and literature teaching.
\end{abstract}

\section{Introduction}

The development of Internet technology has promoted the transformation of various industries, including education industry. In particular, the development of education has been in fierce collision with the modern education technology after China has continuously promoted the reform concept of new curriculum teaching and emphasized the importance of education in quality. The analysis of the specific impact and influence of modern education technology on education is conducive to providing more theoretical strategies and Suggestions for the development of modern education cause. The specific impact analysis should first be based on the correct understanding of modern education technology.

\section{Correct Understanding of Modern Education Technology}

The correct understanding of modern education technology should start from two aspects. First, the basic connotation of modern education technology should be correctly understood, and second, the basic principles should be followed in the application of modern education technology. Only from the perspective of correct understanding, can we correctly analyze and analyze the important impact of it.

\subsection{Basic connotation}

The connotation of modern education technology or the teaching concept advocated by modern education technology is to form a student-centered learning atmosphere. In other words, we should attach importance to independent learning and emphasize the importance of cognitive subjects. In the connotation of modern education technology, students are no longer the receivers of knowledge, but pioneers. They actively explore knowledge, process knowledge, and build knowledge systems. As an auxiliary, teachers help students complete the process of independent learning by using teaching methods or teaching techniques.

For modern education technology, the object of its research is not students or teachers. The object of its study is not a single individual but refers to the specific learning process of students. Modern education technology is actually around quality education to carry out, and its specific research content, it is for collect and design and education resources, recycling and development, to form a more efficient teaching learning resources, into students' self-development "tool", make students be able to complete the study on the basis of individual differences [1].

In addition, modern education technology also emphasizes the connection between theory and 
practice. It points out that education should not be a single battle between teachers and students or a single learning of students themselves. It should be a learning process formed by the combination of modern education technology, students and teachers. Among them, modern education technology provides resources, and teachers play a leading role. They work together to assist students in completing independent study. Therefore, modern education technology is actually a teaching tool based on education, which promotes the reform and development of education teaching methods.

\subsection{Principle analysis}

The application of modern education technology should follow three principles: scientific principle, practical principle and operability principle. Among them, the scientific principle is the basis. The scientific principle itself refers to the application of modern education technology on the basis of teaching content and teaching materials. In short, teachers should first carry out in-depth exploration and mastery of teaching content, and mark and divide key and difficult points. Then, teachers should combine the existing modern education technology with the traditional classroom teaching methods to form a teaching plan. So as to complete the guidance for students [2]. Therefore, modern education technology actually plays the role of "electronic textbooks" in teaching courses, so the scientific nature is the necessary prerequisite for the application of modern education technology.

The principle of effectiveness is based on the principle of scientific, and highlights and emphasizes the key points and difficulties marked. Help students to understand and remember the process from difficult to simple. In this way, the content of education can be ensured to be real, instead of blindly following education mode, which finally makes education become a form of inversion.

The principle of operability is relatively simple. For teachers, no matter how to use any modern education technology to carry out the course teaching, they need to master the basic operation, such as the hardware operation of multimedia devices or the software operation of video, audio and picture interception. In this way, the classroom can be assisted in efficient development.

\section{The Correct Understanding of the Chinese Language and Literature Major}

Chinese language and literature is a major of literature in colleges and universities. Relevant professional courses vary from institution to institution. But it is all about linguistics, literature, writing, aesthetics and so on. Courses such as ancient Chinese and modern Chinese or comparative courses such as modern literature, contemporary literature and foreign literature are usually offered. In this way, we can achieve a comprehensive literature education for students.

The training direction of Chinese language and literature major is more inclined to literary intellectuals. From the perspective of employment situation, students of Chinese language and literature are usually engaged in jobs such as teachers and journalists. This is related to the content and characteristics of Chinese language and literature teaching, and also to people's views on Chinese language and literature major. For a long time, the orientation of Chinese language and literature has been relatively boring and rigid. Students' learning is often based on the theoretical level, and they seldom carry out practical or practical teaching content, so it is difficult to give full play to teaching characteristics [3].

The most prominent aspect of the influence of modern education technology on the teaching of Chinese language and literature is that it inherits the traditional characteristics of Chinese language and literature and realizes the creativity and innovation in its content. At the same time, it USES modern education technology to transform it into highly practical teaching content, realizing the cultivation of "new" talents.

\section{Analysis on the Teaching Influence of Modern Education Technology}

We can analyze the practical application and influence of modern education technology in Chinese language and literature from three aspects. The first is the shift of teaching focus and the 
change of curriculum, the second is the change of teaching form and teaching method, and the last is the improvement of teachers' teaching image and professional quality.

\subsection{Changes in the major and course of teaching focus}

Modern education technology not only strengthens the basic teaching content of education in Chinese and literature, but also sets some other courses related to teaching content, such as administrative secretarial courses, which aim to improve students' practical ability by helping them understand and master some basic skills and knowledge in the field of secretarial science. This enables students to turn what they have learned into practical content, constantly improve their own humanistic quality in the process of practice and enhance their ability to use the Chinese language. In addition, general education courses also use modern education technology to set up a certain network education platform to complete the teaching. Generally speaking, general education courses mainly involve ideological and moral cultivation, college foreign languages, military theory and so on. By setting up the course platform, students can log in the school's platform page directly through the Internet to understand and learn the basic content. This enriches students' spare time and frees up more time for professional literature education to study theory and practice [4].

The transformation of Chinese language course shows the influence of education technology on Chinese language and literature teaching. The Chinese language and literature major realized that education should develop and change with the development of the social situation and keep up with the trend of the social era. The basic courses of traditional Chinese language and literature majors are actually divided into two categories, one is dry literature or language theory, the other is creative writing and appreciation courses. Modern education technology makes the interaction and balance between them. While emphasizing the importance of theory, teachers can also make use of the setting of classroom situations to complete interactive teaching, improve teaching practice, and help students to complete further understanding and application of knowledge.

\subsection{Changes in teaching forms and teaching methods}

After the application of modern education technology to Chinese language and literature major, the following changes have taken place in the teaching form and teaching method. The first is the emergence of "multimedia teaching mode". Teachers can use multimedia to complete basic teaching. Multimedia devices themselves can combine text, images and video together to form a complete media information transmission. Therefore, compared with traditional courses, it is more expressive. In addition to the effective vivid presentation of rigorous content, it can also help students quickly build a knowledge structure, so as to form better and more in-depth learning [5]. In addition, "multimedia teaching mode" can also make the relationship between students and teachers close and form a certain degree of interaction. In fact, teachers are very rich in both experience and knowledge compared with students. Through the guidance of teachers, students can often find the corresponding point quickly, to achieve the effect of one against three. On the basis of the traditional teaching model, teachers become the dominant of the teaching class and control the teaching rhythm. With the help of modern education technology, teachers can separate themselves from the position of "leader", enter the student group and guide students. In this way, students' cognitive subject identity is highlighted in class and their subjective learning activity is better cultivated.

Second, internet-based "networked teaching methods". The construction of teaching platform is mentioned above. The web-based teaching platform itself can integrate a lot of teaching resources and form a system of education, tutoring, testing and integration. With the help of "network teaching methods", we can first realize the sharing of teaching resources. Students can not only learn relevant theoretical knowledge through the network platform, but also obtain more teaching Shared resources through the search of multimedia courseware, and conduct more in-depth learning, thus realizing the process of transferring knowledge through the network. At the same time, the "network teaching method" has changed teachers from traditional teaching scholars to network platform organizers. Teachers can effectively plan students' learning by reasonably dividing and uploading the teaching content progress. At the same time, the course monitoring and inspection 
content of the platform helps students to understand their learning situation. In this way, we can carry out secondary learning activities in a targeted and purposeful way, so as to better integrate and integrate knowledge.

Finally, the emergence of "virtual reality teaching methods". This is a kind of modern education technology unique, applied in the classroom advantage. With the help of Internet technology, we can realize the combination of $3 \mathrm{~d}$ virtual simulation software and classroom content in the classroom system. In this way, students can use this technique when they take courses in Chinese language and literature, such as Greek and Roman myths in foreign literature. By simulating or showing the environment of the time for students, students can better understand and understand the humanistic history of the time and have a deeper understanding and understanding of the teaching content [6]. In addition, the "virtual reality teaching method" can also effectively avoid various possible problems in the real teaching. For example, the appreciation and analysis of aesthetic works of art. Some teachers want to take students into art galleries to see, face to face experience art. At the time, the idea could not be realized because of economic or other factors. But the picture and video itself, there are certain constraints. At this time, with the help of "virtual reality teaching method", we can simulate the appearance of art works in three dimensions. The teaching method with strong sense of science and technology will fully arouse students' curiosity and thirst for knowledge, so that students can better complete their studies.

\subsection{Improvement of teachers' teaching image and professional quality}

In conclusion, the means of modern education technology has brought great changes and influences to the teaching of education in Chinese language and literature, which has also sounded the alarm bell for teachers themselves. Science and technology are progressing, and society is in the process of continuous vigorous development. For teachers, how to combine the development of the current era, constantly improve their professional quality, and improve the quality of classroom teaching with the help of modern education technology has become a problem that needs to be solved at present [7].

The first problem we need to face is the transformation of teachers' role positioning. In the above article, the author also constantly emphasizes that teachers have always been the dominant teacher in traditional teaching, which limits students' ability of independent learning and exploration. Therefore, teachers should change their ideas when modern education technology comes. The classroom should combine the new ideas and requirements proposed by education career, step out from the platform, walk to students' side, become students' partners, study with students and grow up together. Only in this way can we close the relationship between teachers and students, realize happy and diversified teaching, and achieve the realization of teachers' self-value.

In addition, teachers should constantly enrich themselves, that is, improve their professional quality. In traditional teaching, professional quality actually requires teachers to improve in two aspects. The first is the improvement of professional ability. Teachers should constantly enrich their knowledge and form more professional teaching. Secondly, the improvement of teaching ability. Teachers should learn how to make the classroom more interesting and efficient, so that students can learn more knowledge in limited class time. The introduction of modern education technology has split the improvement of teaching professional quality from two aspects to four. In addition to the above contents, teachers also need to strengthen the learning of scientific and technological contents, including simple hardware operations, such as multimedia teaching equipment, and the application of some software, such as basic office software or video editing, and the combination of audio images, etc. As an auxiliary means of education teaching, these are one of the professional skills that teachers should master. In addition, it is necessary to strengthen the further study of education psychology. Teachers should always be aware of their own positioning and know how to get along with students. Teachers should become students' friends, understand students' hearts and guide students' shortcomings, so as to better realize teaching [8]. It can be said that with the advent of modern education technology, teachers have changed from teachers to intellectuals. On the one hand, they have become professional and professional, on the other hand, they have been constantly 
learning other professional knowledge and content.

\section{Conclusion}

Combined with the full text, modern education technology has exerted a great influence on the teaching of Chinese language and literature and has exerted an impact on all aspects. In fact, modern education technology is still developing and improving. Together with education, it is heading for a better future. As the beneficiaries of modern education technology, students should also constantly enrich themselves and study harder.

\section{References}

[1] Liu Rude. Question-based learning: a teaching reform thinking that focuses on constructivism [J]. Education theory and practice, 2015(05):54-57.

[2] Zhang Ling, Zhang Lei. Research on the influence of "modern education technology" public class on the technical ability of pre-service teachers' education [J]. China Dianhua education, 2013(12):114-117.

[3] Wang Cunyou. "Modern education technology" public lecture reform path [J]. China education informatization, 2016(19):73-76.

[4] Feng Rui, Miao Sihui. A review on the 3C3R problem design model for problem-oriented learning [J]. Education, 2014(01):72-76.

[5] Ma Zhiqiang. Review on the research status of Moodle course learning activity design [J]. Research on education electrochemical, 2013(10):105-108.

[6] Liu Dong. PBL and teacher education teaching reform [J]. Journal of Liaoning university of technology (social science edition), 2015(02):65-67.

[7] Wang Zhijun. Use PBL teaching method to cultivate students' innovation and practice ability [J]. Experimental technology and management, 2016(06):32-33.

[8] Liu Baocun. The problem-based learning model of American research universities [J]. China higher education research, 2014(10):61-63. 